\title{
HUBUNGAN JENIS KELAMIN, USIA DAN SKEMA OKLUSI DENGAN GANGGUAN SENDI TEMPOROMANDIBULAR PADA MAHASISWA FKG USU
}

\author{
Ariyani Dallmer*, Mira Ginta Sembiring*** \\ * Departemen Prostodonsia Fakultas Kedokteran Gigi Universitas Sumatera Utara, \\ ** Mahasiswa Fakultas Kedokteran Gigi Universitas Sumatera Utara \\ Sembiring.mira@gmail.com
}

\begin{abstract}
Abstrak
Oklusi fungsional terbagi atas gerakan lateral dan protrusif. Kaninus dan gigi posterior berkontak saat pergerakan lateral. Kontak saat gerakan lateral disebut skema oklusi. Hubungan antara skema oklusi dan Gangguan Sendi Temporomandibular (STM) masih diperdebatkan dalam kedokteran gigi. Etiologi gangguan STM terbagi atas faktor perpetuasi seperti jenis kelamin, faktor predisposisi seperti usia dan skema oklusi. Penelitian ini bertujuan untuk melihat prevalensi dan hubungan antara jenis kelamin, usia dan skema oklusi dengan gangguan STM. Jenis penelitian ini adalah deskriptif analitik dengan metode cross sectional. Sampel penelitian ini adalah mahasiswa FKG USU. Jumlah sampel sebanyak 100 orang. Subjek diperiksa dengan RDC/TMD dan pemeriksaan skema oklusi dengan shim stock. Kemudian dianalisis dengan uji chi square dan kolmogorov smirnov. Hasil dari penelitian ini menunjukkan tidak ada hubungan antara jenis kelamin dan skema oklusi dengan gangguan STM, namun terdapat hubungan antara usia dengan gangguan STM. Penelitian ini juga menunjukkan adanya subjek yang memiliki kombinasi antara skema oklusi canine guidance dan group function.
\end{abstract}

Kata kunci : Jenis Kelamin, Usia, Skema Oklusi, Gangguan Sendi Temporomandibular

\section{PENDAHULUAN}

Oklusi adalah hubungan normal antara bidang oklusal dan insisal dari gigi geligi mandibula dan maksila saat rahang dalam keadaan tertutup. Oklusi terbagi dua yaitu oklusi statis dan oklusi dinamis. Oklusi statis adalah bentuk dan hubungan dari gigi geligi baik dalam satu rahang ataupun antar rahang serta hubungan gigi geligi dengan jaringan pendukung gigi. Oklusi dinamis adalah fungsi gabungan dari gigi geligi, jaringan pendukung, STM, neuromaskular dan sistem nutritif sebagai sistem stogmatognasi. Oklusi eksentrik terbagi atas oklusi fungsional dan oklusi nonfungsional. Oklusi fungsional adalah kontak gigi yang terjadi pada sisi rahang yang menuju ke arah pergerakan mandibula. Oklusi fungsional terbagi atas lateral dan protrusif. Pada gerakan lateral terjadi kontak kaninus dan gigi posterior mandibula dengan kaninus dan gigi posterior maksila pada sisi yang menuju ke arah pergerakan rahang. ${ }^{1}$ Jika yang berkontak hanya kaninus mandibula dan kaninus maksila pada working side disebut canine guidance. Bila gigi posterior mandibula dengan gigi posterior maksila pada working side juga berkontak disebut group function. Canine guidance dan group function merupakan gigi yang memandu saat pergerakan mandibula ke arah lateral. Hal ini disebut dengan skema oklusi. Skema oklusi dapat dievaluasi menggunakan dental floss dan shim stock. $^{2}$

Oklusi idealnya memungkinkan mandibula bertranslasi tanpa hambatan oklusal saat gerakan fungsional sehingga efisiensi pengunyahan pada sisi kerja tidak hilang, distribusi beban aksial lebih merata dan dapat menghindari beban berlebih pada STM. Namun tidak ada parameter oklusal yang secara konsisten berhubungan dengan gangguan Sendi Temporomandibular (STM) serta hubungan oklusi dan STM masih diperdebatkan. Salah satu yang menjadi parameter oklusi adalah tipe skema oklusi. ${ }^{2}$

Gangguan sendi temporo-mandibular (STM) adalah gabungan dari gejala dan tanda yang melibatkan salah satu atau gabungan dari sendi temporomandibular dan otot mastikasi. ${ }^{3}$ Penyebab gangguan STM menurut Bell (1990) terdiri dari tiga faktor yaitu faktor perpetuasi seperti jenis kelamin, faktor predisposisi seperti usia dan skema oklusi, serta faktor inisiasi. ${ }^{4}$

Prevalensi terjadinya gangguan STM lebih tinggi pada wanita disebabkan oleh hormon esterogen yang dominan. ${ }^{5}$ Individu yang termasuk dalam kategori usia 2040 tahun menjadi paling sering mengalami gangguan STM karena rentan mengalami stress. Skema oklusi canine guidance dianggap lebih mengurangi risiko gangguan STM karena posisi dan bentuk kaninus yang menyebabkan gaya terdistribusi merata. ${ }^{6}$ Namun terdapat juga literaturliteratur yang menolak teori tersebut. ${ }^{7,8}$ 
Perbedaan pendapat mengenai hubungan jenis kelamin, usia dan skema oklusi dengan gangguan STM menjadi dasar dari penelitian ini.

\section{BAHAN DAN METODE}

Rancangan penelitian yang digunakan dalam penelitian ini adalah deskriptif analitik dengan metode cross sectional. Populasi dari penelitian ini adalah mahasiswa FKG USU stambuk 2013 sampai 2016. Sampel diambil dengan teknik simple random sampling dan besar sampel ditentukan berdasarkan penelitian sebelumnya. ${ }^{2}$ Jumlah sampel minimum 88 orang. Untuk menghindari drop out, sampel ditambah menjadi 100 orang.

Kriteria inklusi meliputi mahasiswa FKG USU berusia 17-22 tahun, masih aktif kuliah dan bersedia menjadi subjek penelitian, memiliki gigi permanen lengkap sampai molar 2, hubungan gigi posterior klas I Angle dan tidak memiliki penyakit sistemik. Kriteria eksklusi meliputi pernah atau sedang perawatan ortodonti, memakai gigi tiruan, memiliki karies yang besar serta pernah mengalami trauma kepala, wajah atau dagu.

Populasi diobservasi, dilakukan pengurusan surat izin etik dan penelitian dari Komisi Etik dan Depertemen Prostodonsia. Dari populasi diambil 100 subjek berdasarkan kriteria inklusi dan eksklusi. Subjek dibagi berdasarkan jenis kelamin, usia 17-19 tahun dan 20-22 tahun.

Pemeriksaan untuk melihat ada atau tidaknya gangguan STM, subjek terlebih dahulu diwawancara dengan pertanyaan Research Diagnostic Criteria (RDC) Anamnestic Index. Kemudian dilanjutkan dengan pemeriksaan klinis STM berdasarkan Research Diagnostic Criteria TMD (RDC/TMD). Pemeriksaan ini meliputi pemeriksaan riwayat sakit, pola pembukaan mulut, pergerakan rahang secara vertikal (Pembukaan mulut), hubungan insisivus, sakit saat menggerakkan rahang, bunyi pada STM, serta palpasi otot dan STM.

Pemeriksaan skema oklusi dengan menggunakan articulating paper dan shim stock. Terlebih dahulu beri tanda di labial gigi insisivus, kemudian gerakkan mandibula ke lateral 2-3 mm kemudian dengan posisi tersebut instruksikan untuk menggigit articulating paper. Pada daerah yang memiliki tanda lakukan pemeriksaan ulang dengan shim stock. Daerah yang menahan shim stock menandakan bahwa pada daerah tersebut terjadi kontak. Bila yang berkontak hanya kaninus maka disebut canine guidance, bila kontak terjadi pada gigi posterior maka disebut group function, bila skema oklusi saat pergerakan lateral kanan dan kiri berbeda disebut skema oklusi kombinasi.

Setelah data terkumpul maka diolah dengan SPSS. Data prevalensi penderita gangguan STM disajikan dalam bentuk tabel. Hubungan jenis kelamin dan usia dengan gangguan STM di analisis dengan uji chi square. Hubungan skema oklusi dan gangguan STM dianalisis dengan uji kolmogorov smirnov.

\section{HASIL}

Hasil penelitian menunjukkan bahwa dari 100 orang subjek penelitian ditemukan sebanyak 61 orang $(61 \%)$ mengalami gangguan STM dan 39 orang (39\%) tidak mengalami gangguan STM. Dari 50 orang laki-laki ditemukan 27 orang (54\%) mengalami gangguan STM dan 23 orang (46\%) tidak mengalami gangguan STM. Dari 50 orang perempuan ditemukan 34 orang (68\%) mengalami ganguan STM dan 16 orang (32\%) tidak mengalami gangguan STM. Dari 50 orang yang berusia 17-19 tahun ditemukan 23 orang (46\%) mengalami gangguan STM dan 27 orang (54\%) tidak mengalami gangguan STM. Dari 50 orang yang berusia 20-22 tahun ditemukan ditemukan 38 orang $(76 \%)$ mengalami gangguan STM dan 12 orang (24\%) tidak mengalami gangguan STM. Dari 41 orang yang memiliki skema oklusi canine guidance ditemukan 26 orang $(63,4 \%)$ mengalami gangguan STM dan 15 orang $(36,6 \%)$ tidak memiliki gangguan STM. Dari 53 orang yang memiliki skema oklusi group function ditemukan 35 orang $(66 \%)$ mengalami gangguan STM dan 18 orang $(34 \%)$ tidak memiliki gangguan STM.

Dari 6 orang (100\%) yang memiliki skema oklusi kombinasi antara canine guidance dan group function tidak ada ditemukan penderita gangguan STM. (Tabel 1)

Tabel 1. Prevalensi Gangguan Sendi Temporomandibular Berdasarkan Jenis Kelamin, Usia dan Skema Oklusi pada Mahasiswa FKG USU

\begin{tabular}{||l|l|l|l|l|l|l||}
\hline \multirow{2}{*}{ Karakteristik } & \multicolumn{3}{c|}{ Gangguan STM } & \multicolumn{2}{c||}{} \\
\cline { 2 - 7 } & \multicolumn{2}{|c|}{ Ada } & \multicolumn{2}{c|}{ Tidak ada } & \multicolumn{2}{c|}{ Jumlah } \\
\cline { 2 - 7 } & $\mathrm{n}$ & $\%$ & $\mathrm{n}$ & $\%$ & $\mathrm{n}$ & $\%$ \\
\hline Jenis Kelamin & & & & & & \\
- Laki-laki & 27 & 54 & 23 & 46 & 50 & 100 \\
- Perempuan & 34 & 68 & 16 & 32 & 50 & 100 \\
\hline Jumlah & 61 & 61 & 39 & 39 & 100 & 100 \\
\hline Usia & & & & & & \\
- 17-19 tahun & 23 & 46 & 27 & 54 & 50 & 100 \\
- 20-22 tahun & 38 & 76 & 12 & 24 & 50 & 100 \\
\hline Jumlah & 61 & 61 & 39 & 39 & 100 & 100 \\
\hline Skema Oklusi & & & & & & \\
- Canine guidance & 26 & 63,4 & 15 & 36,6 & 41 & 100 \\
- Group function & 35 & 66 & 18 & 34 & 53 & 100 \\
- Kombinasi & 0 & 0 & 6 & 100 & 6 & 100 \\
\hline Jumlah & 61 & 61 & 39 & 39 & 100 & 100 \\
\hline
\end{tabular}

Berdasarkan hasil uji statistik menggunakan uji chi-square diperoleh hasil tidak adanya hubungan antara jenis kelamin dengan gangguan STM dengan $\mathrm{p}=0.151$ (p>0.05). (Tabel 2)

Tabel 2. Hubungan Antara Jenis Kelamin dengan Gangguan Sendi Temporomandibular pada Mahasiswa FKG USU

\begin{tabular}{|c|c|c|c|c|c|c|c|}
\hline \multirow{3}{*}{$\begin{array}{c}\text { Gangguan } \\
\text { STM }\end{array}$} & \multicolumn{4}{|c|}{ Jenis Kelamin } & \multirow{2}{*}{\multicolumn{2}{|c|}{ Jumlah }} & \multirow{3}{*}{$\mathrm{p}$} \\
\hline & \multicolumn{2}{|c|}{$\begin{array}{l}\text { Laki- } \\
\text { Laki }\end{array}$} & \multicolumn{2}{|c|}{$\frac{\text { Perem- }}{\text { puan }}$} & & & \\
\hline & $\mathrm{n}$ & $\%$ & $\mathrm{n}$ & $\%$ & $\mathrm{n}$ & $\%$ & \\
\hline Ada & 27 & 54 & 34 & 68 & 61 & 61 & \\
\hline Tidak Ada & 23 & 46 & 16 & 32 & 39 & 39 & 0.151 \\
\hline Total & 50 & 100 & 50 & 100 & 100 & 100 & \\
\hline
\end{tabular}

Berdasarkan hasil uji statistik menggunakan uji chi-square diperoleh hasil adanya hubungan antara usia 
dengan gangguan STM dengan $\mathrm{p}=0.002(\mathrm{p}<0.05)$. (Tabel 3)

Tabel 3. Hubungan Antara Usia dengan Gangguan Sendi Temporomandibular pada Mahasiswa FKG USU

\begin{tabular}{|c|c|c|c|c|c|c|c|}
\hline \multirow{3}{*}{$\begin{array}{c}\text { Gangguan } \\
\text { STM }\end{array}$} & \multicolumn{4}{|c|}{ Usia } & \multirow{2}{*}{\multicolumn{2}{|c|}{ Jumlah }} & \multirow{3}{*}{$\mathrm{p}$} \\
\hline & \multicolumn{2}{|c|}{$\begin{array}{l}\text { 17-19 } \\
\text { Tahun }\end{array}$} & \multicolumn{2}{|c|}{$\begin{array}{l}20-22 \\
\text { Tahun }\end{array}$} & & & \\
\hline & $\mathrm{n}$ & $\%$ & $\mathrm{n}$ & $\%$ & $\mathrm{n}$ & $\%$ & \\
\hline Ada & 23 & 46 & 38 & 76 & 61 & 61 & \\
\hline Tidak Ada & 27 & 54 & 12 & 24 & 39 & 39 & $0.002 *$ \\
\hline Total & 50 & 100 & 50 & 100 & 100 & 100 & \\
\hline
\end{tabular}

Keterangan: *Hubungan signifikan $\mathrm{p}<0,05$

Berdasarkan hasil uji statistik menggunakan uji kolmogorov smirnov diperoleh hasil tidak adanya hubungan antara skema oklusi dengan gangguan STM dengan $\mathrm{p}=0.126(\mathrm{p}>0.05)$. (Tabel 4$)$

Tabel 4. Hubungan Antara Skema Oklusi dengan Gangguan Sendi Temporomandibular pada Mahasiswa FKG USU

\begin{tabular}{|c|c|c|c|c|c|c|c|c|c|}
\hline \multirow{3}{*}{$\begin{array}{c}\text { Gangguan } \\
\text { STM }\end{array}$} & \multicolumn{6}{|c|}{ Skema oklusi } & \multirow{2}{*}{\multicolumn{2}{|c|}{ Jumlah }} & \multirow{3}{*}{$\mathrm{p}$} \\
\hline & \multicolumn{2}{|c|}{$\begin{array}{l}\text { Canine } \\
\text { Guidance }\end{array}$} & \multicolumn{2}{|c|}{$\begin{array}{l}\text { Group } \\
\text { Function }\end{array}$} & \multicolumn{2}{|c|}{ Kombinasi } & & & \\
\hline & $\mathrm{n}$ & $\%$ & $\mathrm{n}$ & $\%$ & $\mathrm{n}$ & $\%$ & $\mathrm{n}$ & $\%$ & \\
\hline Ada & 26 & 63,4 & 35 & 66 & 0 & 0 & 61 & 61 & \\
\hline Tidak Ada & 15 & 36,6 & 18 & 34 & 6 & 100 & 39 & 39 & 0,126 \\
\hline Jumlah & 41 & 100 & 53 & 100 & 6 & 100 & 100 & 100 & \\
\hline
\end{tabular}

\section{PEMBAHASAN}

Penelitian ini menunjukkan banyak subjek yang tidak mengalami keluhan pada STM, sedangkan setelah pemeriksaan klinis ditemukan subjek lebih banyak yang mengalami gangguan dari pada yang tidak mengalami gangguan STM. Menurut Xia WD (2016) Tingginya prevalensi penderita gangguan STM pada mahasiswa di China memiliki korelasi dengan gejala psychological stress atau ketidak stabilan kondisi psikologis seperti kecemasan. ${ }^{9}$ Pada mahasiswa bidang kesehatan lebih banyak mengalami gangguan STM disebabkan faktor stress dan kecemasan yang lebih tinggi. ${ }^{10}$

Pada penelitian ini ditemukan jumlah penderita gangguan STM baik pada laki-laki maupun perempuan lebih besar dari pada yang tidak mengalami gangguan STM, namun dari subjek yang mengalami gangguan STM jumlah perempuan lebih besar. Hal ini disebabkan perempuan memiliki hormon estrogen yang dominan. Reseptor hormon ini banyak ditemukan pada ligamen STM sehingga meningkatkan kelemahan ligamen. Estrogen juga menurunkan ambang rasa sakit dengan mempengaruhi neuron sistem limbik sehingga perempuan lebih peka terhadap rasa sakit. ${ }^{5}$

Pada kelompok usia 17-19 tahun lebih banyak yang tidak mengalami gangguan STM, sedangkan pada kelompok 20-22 tahun lebih banyak yang mengalami gangguan STM. Individu yang berusia 20-40 tahun lebih sering menderita gangguan STM, hal ini disebakan faktor stress yang bila berlangsung terus menerus menyebabkan gangguan STM. ${ }^{6}$
Skema oklusi paling banyak ditemukan adalah group function. Menurut Sugiaman DH (2011) skema oklusi ini paling banyak dimiliki populasi karena keausan fisiologis yang terjadi akibat adaptasi terhadap fungsi mastikasi. ${ }^{2}$ Menurut Athibian I (2014) banyaknya skema oklusi group function disebabkan pola makan, psikologikal dan stress. ${ }^{11}$ Pada penelitian ini, jumlah penderita gangguan STM baik pada skema oklusi canine guidance dan group function lebih besar dari pada yang tidak mengalami gangguan STM, namun dari subjek yang mengalami gangguan STM jumlah group function yang lebih besar. Menurut Okeson (2008) Hal ini disebabkan canine guidance dianggap lebih mengurangi risiko terjadinya gangguan STM karena lebih sedikit otot yang aktif. Kaninus juga memiliki akar yang lebar dan panjang serta dikelilingi tulang kompak yang tebal sehingga lebih baik dalam mentolerasi gaya yang diterima. Sedangkan Group function lebih banyak kontak yang terjadi sehingga kemungkinan terjadi interference lebih besar dan menyebabkan beban berlebihan pada STM. ${ }^{6}$ Penelitian ini menemukan subjek yang memiliki skema oklusi kombinasi dan seluruhnya tidak memiliki gangguan STM. Tidak ditemukannya gangguan STM dapat disebabkan subjek yang beradaptasi dengan kondisinya. Menurut Okeson (2008) salah satu faktor yang mempengaruhi toleransi fisiologis adalah faktor lokal. ${ }^{6}$ Pada subjek yang memiliki skema oklusi kombinasi terlihat adanya gigi yang atrisi kemungkinan karena proses adaptasi dari tidak tercapainya stabilisasi ortopedik.

Pada penelitian ini tidak ditemukan hubungan antara jenis kelamin dan gangguan STM. Menurut Manfredini D dan Nardini LG (2010) Perempuan lebih berisiko mengalami gangguan STM dalam populasi penderita gangguan STM namun tidak ada hubungan bila dalam populasi yang menderita dan tidak menderita gangguan STM. ${ }^{3}$ Penelitian ini sesuai dengan hasil penelitian Modi P (2012) dimana prevalensi wanita lebih tinggi namun secara statistik tidak ada hubungan. ${ }^{12} \mathrm{Hal}$ ini dapat disebabkan penyebab gangguan STM yang multifaktorial sehingga terjadinya gangguan STM bukan hanya disebabkan oleh satu faktor saja tetapi gabungan dari beberapa faktor seperti usia, stress, traumatik oklusi, crowded, diastema atau kebiasaan buruk.

Berdasarkan hasil uji statistik menggunakan uji chi-square diperoleh hasil adanya hubungan yang signifikan antara usia dengan gangguan STM. Menurut Sena MF (2013) Individu berusia muda memiliki kemampuan yang lebih baik dalam beradaptasi terhadap perubahan dalam sistem mastikasi sehingga meminimalkan terjadinya gangguan STM. ${ }^{13}$ Menurut Okeson (2008) Individu yang termasuk dalam kategori 20-40 tahun menjadi paling sering mengalami gangguan STM. hal ini disebakan pada usia ini seseorang cenderung memiliki kapasitas adaptif yang rendah dan tanggung jawab yang besar sehingga faktor stress yang meningkat. Stress secara terus menerus menyebabkan otot-otot hiperaktif, termasuk otot-otot mastikasi. Bila berlangsung terus menerus menyebabkan otot menjadi kelelahan dan terjadi kejang otot. Tubuh akan berusaha merileksasi otot dengan mengeluarkan zat-zat algogenic seperti bradikinin dan 
prostaglandin. Zat-zat ini selain merileksasi otot juga mengirimkan respon nyeri ke otak. ${ }^{6,14}$ Menurut Barikani A (2008) tingginya tingkat stress disebabkan tekanan akademik, masalah keuangan dan sosial yang terus meningkat. ${ }^{15}$ Pada usia 20-22 tahun subjek sedang dalam fase akhir perkuliahan dan merupakan masa terberat, baik dalam bidang akademik maupun keuangan. Dewasa muda sekarang juga cenderung memiliki kesulitan dalam membangun hubungan sosial disebabkan lebih banyak melakukan kegiatan di dalam rumah dan lebih sering bersosialisasi dengan media sosial dibanding bertatap muka secara langsung. Hal-hal tersebut menyebabkan dewasa muda sekarang lebih mudah terkena stress bila dibandingkan dengan dewasa muda pada terdahulu.

Jumlah penderita yang mengalami gangguan lebih besar dari pada yang tidak mengalami gangguan STM, baik pada skema oklusi canine guidance dan group function. Namun dari subjek yang mengalami gangguan STM terlihat jumlah group function yang lebih besar. Sedangkan 6 orang yang memiliki skema oklusi kombinasi tidak memiliki gangguan STM. Berdasarkan hasil uji statistik menggunakan uji Kolmogorov-Smirnov diperoleh hasil tidak adanya hubungan antara skema oklusi dengan gangguan STM. Hal ini dapat disebabkan oleh jumlah subjek yang tidak merata pada tiap kelompok skema oklusi dan etiologi gangguan STM yang multifaktorial sehingga kemungkinan faktor psikologis atau faktor lain seperti kebiasaan buruk yang berperan dalam terjadinya gangguan STM. Penelitian ini sesuai dengan penelitian Sugiaman DH (2011) dimana tidak terdapat perbedaan yang signifikan antara canine guidance dan group function untuk mengalami gangguan STM. Oleh karena itu, sebaiknya rehabilitasi oklusi lebih di titik beratkan pada kesehatan dan fungsi sistem mastikasi dari pada mengacu pada konfigurasi oklusal tertentu. Baik canine guidance dan group function dapat dianggap sebagai kondisi fisiologis selama rahang dapat berfungsi efisien tanpa adanya kondisi patologis sehingga tidak perlu untuk mengubah skema oklusi ke kondisi tertentu. ${ }^{2}$ Menurut Abduo J (2013) secara historis gangguan STM biasanya dikaitkan dengan faktor oklusal. Namun hubungan antara faktor oklusal dan gangguan STM masih sulit digambarkan secara jelas. Menurut Pullinger dkk (1993), faktor oklusal yang berhubungan dengan gangguan STM ditemukan dalam 15\% kasus gangguan STM. Hal ini menunjukkan bahwa tidak ada hubungan antara skema oklusi dan gangguan STM. Temuan ini sesuai dengan penelitian klinis dimana mengubah parameter oklusal tidak berhubungan dengan perkembangan gangguan STM. Menurut beberapa penelitian termasuk review secara sistematis, tidak ada bukti yang cukup kuat untuk mendukung bahwa mengubah parameter oklusal lebih baik dibandingkan perawatan lain seperti terapi kognitif, pengobatan secara farmakologis dan terapi fisik dalam mengobati gangguan STM. Sebagai tambahan, mengubah skema oklusi tidak mencegah atau mengurangi perkembangan gangguan STM. Karena itu, menurut Abduo J (2013) skema oklusi bukanlah faktor yang mempengaruhi perkembangan gangguan STM. ${ }^{8}$

Kesimpulan penelitian ini, usia memiliki hubungan dengan gangguan STM disebabkan usia 20 tahun ke atas yang memiliki faktor stress lebih tinggi sehingga rentan terhadap gangguan STM. Namun jenis kelamin dan skema oklusi tidak memiliki hubungan dengan gangguan STM karena terjadinya gangguan STM dipengaruhi faktor lain seperti kebiasaan buruk. Pada penelitian ini ditemukan adanya skema oklusi kombinasi antara canine guidance dan group function.

\section{DAFTAR PUSTAKA}

1. Bhalajhi SI. Orthodontic The Art and Science. New Delhi: Arya Publishing House, 2003:55-62.

2. Sugiaman DH, Himawan LS, Fardaniah S. Relationship of Occlusal Schemes with The Occurrence of Temporomandibular Disorders. Journal of Dentistry Indonesia 2011;18(3):63-7.

3. Manfredini D, Nardini LG. TMD Classification and Epidemiology. In: Manfredini D. Current Concepts on Temporomandibular Disorder. Germany: Quintessence Publishing,2010:25-39.

4. Kaur H, Datta K. Prosthodontic Management of Temporomandibular Disorders. Journal of Indian Prosthodontic Society 2013;13(4):400-5.

5. Chisnoiu AM, Picos AM, Popa S, et all. Factors Involved in The Etiology of temporomandibular Disorders: A Literature Review. Clujul Medical 2015;88(4):473-8.

6. Okeson JP. Etiology of Functional Disturbances in The Masticatory System. $6^{\text {th }}$ ed., USA: Elsevier,2008:95-215.

7. Mazzetto MO, Rodrigues CA, Magri LV, et all. Severity of TMD Related to Age, Sex and Electromyographic Analysis. Brazilian Dental Journal 2014;25(1):54-8.

8. Abduo J, Tennant M, McGeachie J. Lateral Occlusion Schemes in Natural and minimally Restored Permanent Dentition: A Systematic Review. Journal Oral Rehabilitation 2013;40(10):788-802.

9. Xia WD, Fu KY, Lu WX, et all. The Prevalence of Temporomandibular Disorder Symptoms in 898 University Students and Its Relationship with Psychological Distress and Sleep Quality. Zhonghua Kou Qiang Yi Xue Za Zhi 2016;51(9):521-5.

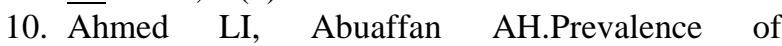
Temporomandibular Joint Disorders among Sudanese University Students. Journal Oral Hygiene Health 2016;4:200.

11. Athiban I, Banu F, Kumar A, et all. Evaluation of Occlusal Scheme with Age Changes in A Group of Dental Students During Their Period of Undergraduation. International Journal Research In Dentistry 2014;4(5):50-9.

12. Modi P, Shaikh SS, Munde A. A Cross Sectional of Prevalence of Temporomandibular Disorders in University Students. International Journal of Scientific Research Publications 2012;2(9):1-3.

13. Sena MF, Mesquita KS, Santos FR, et all. Prevalence of Temporomandibular Dysfunction in 
Children and Adolescents. The Revista Paulista Pediatria 2013;31(4):538-45.

14. Wright EF, North SL. Management and Treatment of Temporomandibular Disorders: A Clinical Perspective. The Journal Manual and Manipulative Therapy 2009;17(4):247-54.
15. Barikani A. Stress in Medical Students. Journal of Medical Education Winter and Spring 2008;11(1,2):41-4. 